\title{
Is There a Near-Term Market for Vehicle-to-Grid Electric Vehicles?
}

\author{
Michael K. Hidrue ${ }^{a} *$ and George R. Parsons ${ }^{b}$ \\ ${ }^{a}$ Massachusetts General Hospital, Boston, MA USA \\ ${ }^{\mathrm{b}}$ School of Marine Science and Policy and Department of Economics, University of Delaware,
}

Delaware, USA

\begin{abstract}
We assess the near-term market for vehicle-to-grid electric vehicles (V2G-EVs) using an internet-based contingent-valuation survey. V2G-EVs are a special breed of electric vehicles used to return power to the grid for ancillary service support or during periods of peak electricity demand. Whether or not these vehicles are economically viable is of interest to policy makers and utility companies. We estimate a demand function for V2G-EVs, consider the importance of different vehicle attributes on demand, and then assess their likelihood of nearterm success on the market. To assess the potential market, we compared consumer's willingness to pay for $V 2 G-E V s$ with the estimated cost of V2G-EVs under different scenarios of battery cost projection. We found, in all scenarios, WTP estimates are lower than projected costs. Range anxiety, stringent V2G contract, and high battery costs are the primary reasons for the outcome.
\end{abstract}

Keywords: vehicle-to-grid (V2G), electric vehicles, willingness to pay

* Corresponding author

E-Mail: mkessete@udel.edu 


\section{Introduction}

Concerns about global warming and energy security have increased interest on electric vehicles (EVs). The United States, Japan, China, and many European countries are spending billions of dollars to develop EVs. The Obama Administration, for example, allocated \$2.4 billion toward the development of EV batteries as part of the 2009 stimulus package (American Recovery and Reinvestment Act). Those efforts have encouraged research on EVs and several innovations of EV design are in the pipeline. One such innovation is the design of EVs with vehicle-to-grid (V2G) capability.

V2G refers to the flow of power from EVs or Plug-in hybrid electric vehicles (PHEVs) to a power grid. The basic idea behind the concept of $\mathrm{V} 2 \mathrm{G}$ is to use vehicle batteries for gridrelated storage services while a car is parked. The average US car is parked $95 \%$ of the time (Pearre et al., 2011) and can represent a significant resource to the grid. The grid can use EVs' battery as a reserve for peak load demand, reserve to meet unforeseen equipment failures (spinning reserve), or as a reserve for frequency regulation (regulation up and regulation down). EVs that can provide these functions are called Vehicle-to-Grid Electric Vehicles (V2G-EVs).

Designing EVs and PHEVs with V2G capability has economic and environmental benefits. Economically, both consumers and power companies benefit. Consumers earn money by selling V2G services to the grid. Several studies have estimated the economics of providing V2G service to drivers and depending on the assumptions built into the estimation, consumers can earn as high as $\$ 4000$ per year (Kempton and Tomic, 2005; White and Zhang, 2011). Sioshansi and Denholm (2010) framed their analysis in terms of payback period and found providing V2G services reduces the payback period for PHEVs from over nine years to around seven years. Organizations that own fleets of vehicles and who have predictable driving patterns may also benefit from switching to V2G enabled vehicles. Noel and McCormack (2014) found, compared to diesel fueled school buses, V2G enabled electric school buses can save school districts about $\$ 6000$ per seat in net present value. Similarly, De Losi Rios et al. (2012) found, compared to diesel-fueled trucks, V2G enabled trucks have 5-11\% lower lifetime ownership cost. These estimates indicate the potential for V2G enabled vehicles. Kempton and Tomic 
(2005) indicate the reserve market that is economically feasible for V2G enabled vehicles has a twelve billion dollar annual market value. If EVs are designed with V2G capability, drivers can tap into this market.

Power companies may also benefit economically, since V2G reserve has faster response rate, better economy, and higher reliability than generated reserve (Lefeng et al., 2013; Guille and Gross, 2009). For example, Sioshansi and Denholm (2010) estimated a fleet of PHEVs providing V2G service could save the grid up to $\$ 200$ annually per vehicle. These savings come mainly from reducing the need to reserve controlled generator capacity. Power companies will also see improved efficiency with large scale V2G-EV deployment, since V2G-EVs are more likely to charge during night when there is excess capacity. This may increase their profit significantly. For example, Weis, et al. (2014) found controlled charging - shifting charging of PHEVs to off peak hour - results in significant cost savings to the system and the benefits are larger with higher wind penetration.

The environmental benefits of V2G technology come in two ways. First, V2G-EVs will help to reduce emission by replacing generators currently providing reserve service. Second, V2G-EVs will support intermittent sources of energy such as wind and solar by providing storage for excess power during periods of high output and supply power during periods of low output. These environmental benefits may appeal to policy makers and there have been several initiatives to support the development of V2G technology. For example, in 2002, the California Air Resource Board and the California Environmental Protection Agency sponsored a study to evaluate the feasibility and practicality of V2G power for regulation service (Brooks, 2002). The Department of Energy (DOE), on its part, developed regulations and building code requirements for V2G vehicles (Briones et al., 2012) and the Federal Energy Regulation Commission issued an order revising existing regulation so that participants like $\mathrm{V} 2 \mathrm{G}$ vehicles get fair payments (FERC, 2011).

However, these benefits of V2G technology also come with some costs. In particular, there are three costs associated with providing V2G service. First, configuring EVs and PHEVs to provide V2G service involves additional electronic, communication, and connection costs. These costs are relatively small and are often incorporated into the calculation of net revenue from V2G service. Second, providing V2G service reduces battery life. Battery depreciation due to $\mathrm{V} 2 \mathrm{G}$ service is also often incorporated in the calculation of net revenue from $\mathrm{V} 2 \mathrm{G}$ service, but 
there is no consensus in the extent of the damage to battery life. Peterson et al., (2010) found mild effect of V2G service on battery wear. Bishop et al., (2013), on the other hand, found providing V2G service results in multiple battery replacement over the vehicle lifetime. The third cost is inconvenience cost associated with providing V2G service. Providing V2G service limits the freedom and mobility of the driver to some degree. The vehicle is not available for driving for the hours contracted to provide V2G service and it may have only limited power for immediate driving after those hours. Drivers may perceive this as inconvenience cost. Unlikely the other two costs, inconvenience cost is largely ignored in the calculation of revenue from V2G service or implicitly assumed to be less than the revenue from V2G services. Sovacool and Hirsh (2009) challenge this assumption. Inferring from the experience of other nontraditional energy technologies, they point out consumers generally fail to properly evaluate future savings from new energy technologies, apply very high discount rates when assessing such benefits, and require large compensation for perceived loss of freedom and mobility when considering to switch to EVs. If these consumer behaviors apply in the decision to switch to V2G enabled vehicles, the estimated revenues from providing V2G service may not be large enough to persuade consumers. To the best of our knowledge, there is no study that empirically compared the inconvenience cost and net revenue of providing V2G service to consumers. In this study, we try to fill this gap in the literature by designing a stated preference survey of potential car buyers.

We used a contingent valuation (CV) design to estimate consumer willingness to pay (WTP) for a V2G-EV that provides grid service in return for annual revenue payment. To capture the inconvenience cost of providing V2G service, we proposed a V2G contract that requires the car to be available for certain number of hours per day to provide grid service and a minimum driving range the vehicle will have after each episode of providing service for immediate driving needs of the driver. The value for these attributes is set similar to those assumed in the literature for calculating net revenue from V2G service. The revenue payment is also set in the neighborhoods of the revenues estimated in the literature.

The balance of the paper is organized as follows. The next section presents the design of the survey, the characteristics of the data collected, and the econometric model used to analyze the data. Section three presents estimation results and section four assesses the market for EVs in the near-term. Section five presents conclusion and policy implications of our findings.

\section{Materials and Methods}




\subsection{Study Design}

As noted above we designed a stated preference survey of car buyers in the US. The objective of the study was to assess consumer preference for EVs and V2G-EVs. For EVs to provide reliable grid service, there must be a certain number of $\mathrm{V} 2 \mathrm{G}-$ ready vehicles plugged to the grid, at any point in time. That number must be large enough to generate the minimum capacity required for participating in a particular power market. Moreover, since the primary purpose of the vehicles is transportation and grid service is secondary, one needs more vehicles than the number required to generate the minimum capacity. This implies, for V2G-EVs to provide grid service, there must be significant adoption of EVs in the market and considerable number of EV owners must be persuaded to participate in the market for $\mathrm{V} 2 \mathrm{G}$ service. To assess this dynamics, we designed three choice experiments.

The first experiment sought to assess the potential market for EVs and identify the factors that mater to consumer choice of EVs as a first step towards assessing the potential for V2GEVs. The second experiment was designed to assess consumer preference for $\mathrm{V} 2 \mathrm{G}$ contract terms. Even with a widespread adoption of EVs, participation of EV owners in V2G service will depend on how they perceive the terms of participation (V2G contract terms). This part of the study used choice experiment design to assess the tradeoffs consumers will make in V2G service market. The third experiment used a CV design to assess the potential market for V2G-EVs in the near future. The design of the first two experiments and analysis of the data can be found in Hidrue, et al. (2011) and Parsons, et al. (2014), respectively. Here, we will focus on the CV question.

The CV questions were designed to assess potential market for V2G-EVs in the near future. The proposed V2G-EV has two sets of attributes: attributes related to the design of the vehicle and attributes related to the design of $\mathrm{V} 2 \mathrm{G}$ contract. Table 1 presents the attributes used, their definition, and the levels used in the design. To make the choice exercise as realistic as possible, we set the value of the vehicle attributes similar to the specification of a prototype V2G-EV (eBox). The vehicle can drive 140 miles on full charge, charge 50 miles of driving 
range in one hour, cost the equivalent of $\$ 1.00 /$ gallon of gas to charge, perform better than a comparable gas vehicle (5\% faster), and generate less pollution ( $75 \%$ lower) than a comparable gas vehicle.

The V2G contract portion of the CV question has three attributes: guaranteed minimum driving range, required plug-in time, and annual cash back. We used attribute values similar to those assumed in the literature. Guaranteed minimum driving range refers to the amount of energy the grid reserves for immediate driving needs of the driver while using the vehicle's battery for V2G service. The value for this attribute is usually set with a goal of meeting the driving needs of the average driver in the study area. The average driving range in the USA is below 40 miles/day; we set the guaranteed minimum driving range at 25 miles. In estimating potential revenue from V2G service, Kempton and Tomic (2005) assumed 20 miles. Required plug-in time refers to the number of hours per day the vehicle is required to provide V2G service. In general, the literature assumes if the vehicle is parked, it is available to provide V2G service. The average car in the US is parked 23 hours per day. We used 20 hours. For estimating potential revenue from V2G service, Kempton and Tomic (2005) assumed 18 hours and White and Zhang (2011) assumed 22 hours. Finally, cash back refers to the revenue a V2G vehicle can earn from providing V2G service. Roughly, the potential revenue depends on the number of hours the service is provided and the energy available for $\mathrm{V} 2 \mathrm{G}$ service (maximum capacity - energy required to meet minimum guaranteed driving range). Kempton and Tomic (2005) estimated \$2555 per year for a vehicle with 27kWh and 18 hours of plug-in time. White and Zhang (2011) estimated over $\$ 4000 / y e a r$ for a PHEV with $16 \mathrm{kWh}$ and 22 hours of plug-in time. We used $\$ 4000 /$ year.

The proposed V2G-EV has also two additional attributes: vehicle model and availability of range extender. We included vehicle model in response to feedback from focus group participants. During the focus group discussions, many people expressed displeasure with the eBox as an EV. To assess the impact of vehicle model on choice of EVs and V2G-EVs, we included an alternative model (Honda Civic) in our design. Range extender refers to availability of an on-board backup gasoline engine that extends the driving range of an EV after the battery runs out of charge. General Motor's Chevy Volt is an example. Since using EVs for V2G services can create additional range anxiety for drivers, we wanted to test the value of a range extender in V2G-EV choice. 
Our survey design also included a treatment effect to capture yea-saying tendency. Yeasaying tendency is a phenomenon where survey respondents in a hypothetical setting tend to say "yes" for a proposed product at a price higher than their true WTP (Blamey et al., 1999). This results in overstated WTP estimates (Holmes and Kramer, 1995; Boyle et al., 1998). In our case, we were concerned respondents may vote "yes" to show their support for V2G-EVs at a price higher than their true WTP. To capture such tendencies, we administered a split sample survey where approximately half of the respondents received a version of the survey with a treatment effect. The treatment effect, shown as the third option in Figure 1, is similar to the dissonanceminimizing (DM) format used in Blamey et al., (1999). It allowed people to say "I like the idea of V2G-EVs"(registering favor with concept) "but not at these prices"'(showing their real likelihood of purchase).

Finally, we asked respondents to assume the following points in their choice. Except for the attributes specifically mentioned in the CV design, the V2G-EV is similar to a comparable conventional gasoline vehicle in other features (safety, convenience, etc.). The vehicle comes with battery warranty for the life of the vehicle. Consumers would be provided with an outlet (charger) at home and many worksites and public parking places would have outlets. Also for the sake of the survey, consumers were asked to assume no government incentives or rebates for V2G-EVs.

\subsection{Data Characteristics}

The survey was administered online. Respondents were randomly drawn from a national panel of respondents administered by Survey Sampling International (SSI). A total of 3029 respondents, each answering two CV questions, completed the survey. Table 2 compares the characteristics of the sample with the characteristics of a census data for that period. Overall, the sample provided a good representation of US households. The survey and the census have similar distributions for many key demographic variables including age, income, type of residence, and number of vehicles in a household. The sample slightly under represents male and less educated people. The later is mainly because we excluded respondents who had indicated to spend less than $\$ 10,000$ on their next vehicle. 
In addition to demographic information, we also collected attitudes and perceptions towards the environment and EVs. Two questions focused on environmental issues. The first asked how much a threat, if any, climate change poses to the world and the second question asked how much change, if any, the respondents made in their life style and shopping habit in the past five years to help the environment. Most of them said climate change poses either major $(44 \%)$ or minor $(38 \%)$ threat, but only few them (23\%) said they made major change in their life style to help the environment.

Another set of questions focused on respondents' perception of EVs vis-à-vis conventional gasoline vehicles. These questions were designed to identify the factors that appeal to potential buyers as well as the factors that concern them. We provided respondents with a list of the main advantages and disadvantages of purchasing EV and asked them to rate the relevance of each factor in their purchasing decision. Tables $3 \mathrm{~A}$ and $3 \mathrm{~B}$ summarize the results for the advantages and disadvantages, respectively. Among the advantages, lower fuel cost has the highest rating followed by lower dependence on foreign oil, and lower pollution. Among the disadvantages, higher purchase price concern most to respondents followed by range anxiety and longer charging time.

\subsection{Econometric Model}

In modeling choice data, preference heterogeneity is a key concern. In our case, this is particularly true for two reasons. First, earlier EV studies have documented significant level of heterogeneity in EV choice (Beggs et al., 1981; Calfee, 1985; Brownstone and Train, 1999; Hidrue et al., 2011). Second, our interest is not in predicting average market share, but in exploring whether there is a niche market for V2G-EVs. A model that allows for preference heterogeneity provides better prediction in such circumstances.

We estimated standard and latent class binary logit models. The latent class model assumes preference heterogeneity in the population can be captured by a finite number of preference classes. Preferences are the same within class but differ across classes. Each individual in the population can be considered as randomly drawn from one of these classes. The model captures preference heterogeneity by estimating a separate set of preference parameters for each class. The preference classes are called latent because the number of classes in the 
population and membership into these classes is latent to the analyst. For a given class size of $\mathrm{S}$, the probability of choosing a V2G-EV in our survey is given by the following equation:

$$
P_{n j}=\sum_{s=1}^{S} Q_{s} \pi_{n j / s}
$$

$$
\text { Where: } \quad \begin{aligned}
Q_{n s} & =\frac{\exp \left(\theta_{s} Z_{n}\right)}{\sum_{s=1}^{S} \exp \left(\theta_{s} Z_{n}\right)} \\
\pi_{n / s} & =\frac{1}{\left[1+\exp \left(\alpha_{s}+\beta_{s} X_{n}\right)\right]}
\end{aligned}
$$

$\mathrm{S}=1, \ldots \ldots, \mathrm{S}$, index for classes

$\mathrm{n}=1, \ldots \ldots \mathrm{N}$, index for respondents

$\mathrm{j}=$ index for choices ("Yes" or "No")

$\mathrm{Z}_{\mathrm{n}}=$ Vector of individual specific covariates

$\Theta=$ Vector of class specific parameters corresponding to $Z_{n}$

$\mathrm{X}_{\mathrm{nj}}=$ Vector of variables describing V2G-EV

$\beta=$ Vector of class specific parameters corresponding to $X_{\mathrm{nj}}$, and

$\alpha=$ A class specific constant for the model

The first expression in equation (1) represents the class membership model. It predicts the likelihood that a randomly selected individual belongs to class $\mathrm{S}$. The covariates in the class membership model $\left(\mathrm{Z}_{\mathrm{n}}\right)$ can be demographic variables, attitudinal constructs, perception measures, or any individual specific variable that is expected to affect classification probabilities. The second expression in equation (1) represents the conditional random utility model, which predicts the probability of choosing a V2G-EV given the individual belongs to class $S\left(\pi_{\mathrm{j} / \mathrm{s}}\right)$.

For a given $\mathrm{S}$, equation (1) is estimated using maximum likelihood. The procedure estimates $S$ vectors of $\alpha_{s}$, and $\beta$, and S-1 vectors of $\theta_{s}$. One vector of $\theta_{s}$ is normalized for identification. The class size $\mathrm{S}$ is determined using information criteria measures such as the Akakie Information Criterion (AIC), the consistent AIC (cAIC), and the Bayesian Information 
Criterion (BIC) ${ }^{1}$. However, the different criteria may not always select the same number of classes or the parameter estimates for the selected class size may have lower quality than an alternative class size. In such cases, the researcher's judgment is essential in selecting the optimal class size (Swait, 2007).

\section{Results}

In this section, we present estimation results. Table 4 presents the definition and descriptive statistics of the variables used in our models. Tables 5A and 5B present the results of the conditional random utility and class membership models, respectively. Table 5A also presents results from standard binary logit model for reference. We begin our discussion with how we determine the number of classes for the latent class model.

\subsection{Number of Latent Classes}

We estimated a latent class model with two, three, and four classes. For each class, we calculated the AIC, cAIC, and BIC values. The AIC suggests a four-class model while the cAIC and BIC suggests a three-class model. Further examination of the estimated parameters shows many of the parameters in the four and three class models are statistically insignificant (with large standard errors) and some of them have a wrong sign. Therefore, we chose the two-class model for our analysis.

Examining the coefficients of the conditional random utility model (Table 5A) and the class membership model (Table 5B) shows respondents in the smaller class (27\% of the sample)

\footnotetext{
${ }^{1}$ The formula for calculating each measure are given by: $A I C=-2 L L(\beta)+2 K, c A I C=-2 L L(\beta)+K(\ln (N)+1)$, and $\mathrm{B} I C=-2 L L(\beta)+K \ln (N)$ : Where $\mathrm{LL}(\mathrm{B})$ is $\log$ likelihood value at convergence, $\mathrm{K}$ is the total number of parameters estimated, and $\mathrm{N}$ is sample size.
} 
have a higher proclivity towards V2G-EVs than those in the larger class (73\% of the sample). In line with their preference, we refer respondents in the smaller class as V2G-oriented class and those in the larger class as GV-oriented class (as in gasoline vehicle oriented) ${ }^{2}$.

\subsection{Conditional Random Utility Model}

Table 5A presents parameter estimates for the conditional random utility part of the latent class model ${ }^{3}$. All the coefficients have the right sign and most of them are statistically significant at $5 \%$ level. Comparing the coefficients across the two classes shows the degree of preference heterogeneity in the population. Several variables in Table 5A are worth examining

First, consider the dummy for yea-correction. We administered a split sample survey with approximately half of the sample receiving a version of the survey with correction for yea-saying tendency and the remaining half without correction. The dummy for yea-correction has a value of one if the observation came from the sample with yea-saying correction and zero otherwise. The coefficient for the dummy has a negative sign, which indicates the sample with yea-saying correction has a lower tendency of choosing V2G-EVs than the sample without yea-saying correction. However, the yea-saying coefficient is significant only in the V2G-EV oriented class. This implies yea-saying tendency is likely to exhibit among consumers with high proclivity towards EVs.

The estimates for vehicle model are also interesting. The coefficient for the Civic model dummy is significant in both classes indicating that respondents prefer the Civic over the eBox. The two classes differ slightly in how much they value the Civic over the eBox. We are not surprised that people prefer the Civic over eBox, since many people have also indicated this during the focus group discussion and in the comment section of the actual survey. What surprised us is how much they dislike the eBox. This finding is important for automakers planning to produce new EVs. Our results suggest vehicle model can have a significant role on the success of new EVs in the market.

\footnotetext{
${ }^{2}$ This finding is similar to what we found in our earlier studies for conventional EVs (Hidrue et al. 2011) and V2G vehicles (Parsons et al., 2014). In both papers, we found consumer preferences can be summarized by a two-class model.

${ }^{3}$ Table $5 \mathrm{~A}$ also presents parameter estimates from a standard binary logit model for reference. However, our discussion focuses on the results of the latent class model, since it fits the data better and has advantage in capturing preference heterogeneity.
} 
Finally, the results for availability of range extender are important. The coefficients for the range extender dummy imply people in general value having range extender, but differ in how much they value it. People in the V2G-oriented class have higher value for range extender than people in the GV-oriented class. The probability weighted WTP is $\$ 4,100$. This amount is lower than what it will likely cost to have range extender. For example, in comparing lifecycle cost of an EV to a similar gasoline powered vehicle, Werber et al. (2009) estimated the cost of internal combustion engine (ICE) and transmission at \$7,400 - much higher than the WTP value implied in our estimates.

\subsection{Class Membership Model}

Table 5B presents parameter estimates for the class membership model. For identification purposes, the coefficients for the GV-oriented class are normalized to zero. The coefficients in Table 5B represent the contribution of each attribute to the probability of being in the V2Goriented class. A positive sign indicates having that characteristic increases the probability of being in the V2G-oriented class and decreases the probability of being in the GV-oriented class. For example, age has a negative sign. This indicates as age of a person increases, his/her likelihood of being in the V2G-oriented class decreases and the likelihood of being in the GVoriented class increases. Table 5B also reports the odds ratio. The odds ratios indicate the relative odds of a person being in the V2G-oriented class relative to the GV-oriented class. For example, the odds ratio of 2.1 for being from California indicates that a person from California is 2.1 times more likely to be V2G-oriented than a person from the rest of the United States.

Examining the coefficients in Table 5B shows being from California, expecting higher gas prices in the future, having plans to purchase hybrid vehicle, having a place to install EV charger at home (outlet), having a green life style, and being an "early adopter" increase the likelihood of being in the V2G-oriented class. These results are all expected. On the other hand, having a BA or higher-level of education, age, and being from multicar household decreases the likelihood of being in the V2G-oriented class. Age was expected. Earlier studies have documented that older drivers tend to be less interested in EVs than younger drivers (Ewing and Sarigollu, 1998). Having a BA or higher degree is a surprise. Perhaps it has to do with this particular type of V2G-EVs. Earlier studies have found having a college education increases the 
likelihood of purchasing EV (Brownstone and Train, 1999). Being from a multicar household also sounds counter intuitive. Analysts have often assumed multicar households are more amenable to EVs than single vehicle households. In fact, the early EV studies sampled only multicar households (Beggs et al 1981; Califee, 1985; Kurani et al., 1996). The logic for this stems from the fact that EVs have limited driving range and multicar households would not be constrained by EV's limited driving range since they have a reserve car. Our study provides no support for this assumption. Ewing and Sarigollu (1998) have also found similar result.

\section{Discussion}

In this section, we assess the market for $\mathrm{V} 2 \mathrm{G}-\mathrm{EV}$ s in the short-run. We arbitrarily refer to a period of five years $(2013$ - 2018) as a short run period. We assess potential market for V2GEVs by comparing WTP and cost of production estimates. We begin our analysis by discussing the estimation of WTP, followed by the estimation of production cost.

\subsection{Estimating WTP for V2G-EVs}

We used coefficients from Tables 5A and 5B to estimate WTP for four V2G-EV models:

1. eBox without range extender

2. eBox with range extender

3. Civic without range extender

4. Civic with range extender

A person's WTP for each vehicle, conditioned on being in class S, is the amount of money that makes the person indifferent between purchasing and not purchasing the vehicle. In our model, WTP takes the form:

$$
W T P_{n j / s}=-\frac{\gamma_{s}+\beta_{R E / s} * R E+\beta_{\text {civic } / s^{*} \text { Civic }}}{\beta_{\text {price } / s}}
$$


Where $\gamma_{s}=\alpha_{s}-\beta_{\text {yea/s }}$ is the constant of the model adjusted for yea-saying tendency; RE is a dummy for range extender; and Civic is a dummy for vehicle model.

Equation (2) calculates WTP of each respondent conditioned on being in class S. In our model, no one belongs entirely to one class. Instead, each individual is partly V2G-oriented and partly GV-oriented with a varying degree of membership. Following Boxall and Adamowicz (2002), we calculated the WTP for each person as the probability weighted average WTP:

$$
W T P_{n j}=\sum_{s=1}^{S} W T P_{n j / s} * Q_{n s}
$$

Where S represents class (V2G-oriented or GV-oriented) and $\mathrm{Q}_{\mathrm{ns}}$ represents membership probability in class $\mathrm{S}$.

We used equation (3) to calculate unconditional WTP for each respondent in our survey. Figure 2 presents the distribution of the WTP in the sample for the four vehicles. The median WTP ranges from $\$ 10,200$ for the eBox model without range extender to $\$ 22,900$ for the Civic model with range extender. The maximum WTP ranges from $\$ 14,800$ for the eBox model without range extender to $\$ 31,800$ for the Civic model with range extender. These values tend to be low - for some models even lower than the price of a comparable gasoline vehicle.

There are two possible explanations why the WTP estimates are low. First, there is range anxiety. The V2G-EVs used in our survey has a maximum of 140 miles on full charge and it takes around three hours to fully charge the battery. For the average person, the inconvenience of range anxiety may outweigh the environmental and fuel cost benefits of V2G-EVs. In Hidrue et al. (2011), we found the range anxiety associated with an EV of similar configuration (reducing driving range from 300 miles to 150 miles and increasing charging time from 10 minutes to one hour for 50 miles of charge) reduces WTP by about $\$ 10,000$ while the added value of the environmental and fuel cost benefits of a similar configuration (reducing pollution from $25 \%$ to $75 \%$ lower and reducing fuel cost from $\$ 2.8$ /gallon to $\$ 1.00 /$ gallon) increases WTP by about $\$ 7,400$. 
Second, the V2G contract used with the proposed V2G-EV was very restrictive and had a net negative value on the WTP estimates. The proposed V2G contract requires each driver to plug-in 20 hours everyday (on average), provides a guaranteed minimum driving range of 25 miles only, and pays $\$ 4000$ annually in return. In Parsons et al., (2014), we found respondents associate high inconvenience cost with restrictive contracts. We also found respondents discount revenue from $\mathrm{V} 2 \mathrm{G}$ contracts heavily. For example, we found increasing required plug-in time from 5 hours to 20 hours and lowering minimum guaranteed driving range from 125 miles to 25 miles reduces WTP by $\$ 16,600$ for the average person while $\$ 4000$ annual cash back payment increases WTP by $\$ 8,400$ only. Assuming respondents were consistent in their preference throughout, this implies the V2G contract used in the CV part of the survey reduced WTP by over $\$ 8000$. Needless to say, this amount implies, without the V2G contract, the median WTP estimates would have been higher than the price of comparable gasoline vehicles for all models despite the effect of range anxiety.

\subsection{Estimating Cost of V2G-EVs}

Since V2G-EVs are not on the market, estimating their present and future cost is difficult. However, using some assumptions, we can make a reasonable guess that can help us to assess the potential market for V2G-EVs. For our purpose, we decompose the total cost of V2G-EVs into four parts: battery cost, cost of electric motor and related accessories, cost of backup ICE and related accessories, and cost of vehicle body parts (total cost of the vehicle minus battery cost and engine costs).

We estimated battery costs using the DOE's battery cost forecasts (AEO, 2012) ${ }^{4}$. The DOE forecasts battery cost under two scenarios: a reference case scenario and a high technology case scenario. The reference case scenario is a conservative scenario in which battery costs are projected to decline slowly. On the other hand, the high technology case scenario is an aggressive forecast that assumes a significant breakthrough in battery technology. To provide the

\footnotetext{
${ }^{4}$ It is important to take the battery cost forecasts with great caution. Previous forecasts of decline in battery cost from the DOE have not been realized. For example, in a 2009 forecast that we referred in our earlier study (Hidrue et al., 2009), the DOE forecasted battery cost to drop to $\$ 300 / \mathrm{kWh}$ by 2014 . The revised forecasts for 2014 are now $\$ 742 / \mathrm{kWh}$ in the reference case scenario and $\$ 523 / \mathrm{kWh}$ in the high tech case scenario.
} 
reader with a full range of the technological possibilities, we used both forecasts in our analysis. Table 6 presents these estimates for the four vehicles considered in our analysis 5 .

Table 7 presents the non-battery cost estimates. These costs are calculated as follows:

Vehicle with range extender

= Price of comparable ICE vehicle

+ price of electric motor and associated parts

Vehicle without range extender

$=$ Price of comparable ICE vehicle - cost of ICE

+ price of electric motor and associated parts

We identified the Scion XB and the Honda Civic XL Sedan as the comparable ICE equivalents of the eBox and the Civic models, respectively. In fact the eBox was not manufactured initially as electric vehicle, but was converted from Scion XB (Werber et al., 2009). The Civic used in our survey is a Honda Civic sedan. Hence the two provide a good proxy for cost of vehicle body parts. We used 2013 prices for our calculation. For the cost of electric motor and ICE, we used estimates from Werber et al. (2009). In a study that compared the lifecycle cost of eBox and Scion XB, they estimated the cost of electric motor and associated parts at $\$ 10,000$ and the cost of ICE at $\$ 7,400$. We used these cost estimates for both the eBox model and the Civic model.

\subsection{Comparing WTP and Cost of V2G-EVs}

Table 8 compares WTP and total cost estimates for the four vehicles used in our analysis. The WTP numbers represent top one percent of the WTP distribution for the sample. In other words, we are focusing on the WTP of the consumers with the highest willingness to pay for V2G-EVs. The costs are the sum of battery and non-battery cost estimates from Tables 6 and 7. Because battery costs account for more than half of the total cost and future battery costs are difficult to predict, we present the total cost under two battery cost scenarios. Table 8 indicates,

\footnotetext{
${ }^{5}$ Battery cost for the four vehicles is the same, since the four V2G-EVs have the same driving range. Each vehicle has a maximum of 140 miles on full battery. Assuming an efficiency rate of $1 \mathrm{kWh}=4$ miles, each vehicle has a battery size of $35 \mathrm{kWh}$. The total battery cost is calculated by multiplying the per kWh cost by the battery size $(35 \mathrm{kWh})$.
} 
even under the most aggressive battery technology scenario, the WTP estimates are lower than the corresponding total cost for all four vehicles. Our results suggest that V2G-EVs are unlikely to make inroads in the period under consideration.

There are two caveats to consider in interpreting our findings. First, we did not account for the current federal subsidy, since we wanted to compare real costs and WTP estimates. Currently, V2G-EVs are qualified for a federal subsidy of $\$ 7,500$. Some states, such as California, also provide additional subsidies for EVs. With such subsidy and assuming the high tech battery cost scenario, some of the V2G-EV models in our study can achieve one percent market share. Second, our WTP estimates are based on a data collected in 2009. It is possible, with more EVs and PHEVs coming to the market, consumers' perception of V2G-EVs and hence their WTP, may have improved since then.

\section{Conclusion}

We used a CV survey to assess potential market for V2G-EVs in the near future. A total of 3029 respondents completed the survey, each answering two CV questions. The proposed V2G-EV is a prototype vehicle that could be on the market, provided there is demand for it. We assessed potential demand for V2G-EVs by comparing WTP estimates with projected cost of producing V2G-EVs under different battery cost scenarios. In all scenarios, we found WTP estimates are lower than projected costs. The primary reason for this outcome seems to be range anxiety, stringent V2G contract, and high battery cost.

There are several policy implications to draw from our findings. First, the low WTP estimates are in part due to a stringent V2G contract used in our study. The policy implication from this is that power aggregators should design a less restrictive $\mathrm{V} 2 \mathrm{G}$ contract to attract consumers. Reducing the number of required plug-in hours and increasing guaranteed minimum driving range will reduce the inconvenience cost of V2G contract and increase WTP for V2GEVs. 
Second, the low WTP estimates are also in part due to a high implicit discount rate respondents' use to value future earnings from V2G contracts. Parsons et al., (2014) found respondents used 53\% discount rate in valuing revenue from V2G contracts. Power aggregators can avoid the high discount rate and there by increase WTP for V2G-EVs by providing consumers a contract that pays in advance, in the form of subsidy, in exchange for signing V2G contract. Cell phone companies use similar strategy to attract consumers.

Third, we found vehicle model plays an important role in WTP for V2G-EVs. Designing V2G-EVs as a Civic instead of eBox increased WTP by $\$ 9,000$ in our sample. This is important finding for automakers planning to produce new EVs. It suggests the choice of model type can play a significant role on its success in the market.

Finally, we also found significant yea-saying tendency for V2G-EVs in our sample. Failure to account for this would cause overstated WTP estimates. This finding reinforces earlier findings of hypothetical bias in WTP estimation of pro-environmental goods and calls for researchers in the area to use some form of capturing yea-saying tendency. The approach we used is similar to the approach used in Blamey et al., (1999) and worked fine in our case.

\section{Acknowledgement}

The authors wish to thank Willett Kempton, Meryl P. Gardner, and Jonathan Lilley for their contribution in the design and development of the survey. This research was supported by funding from the U.S. Department of Energy, Office of Electricity (DE-FC26-08NT01905). 
Table 1: Attributes and Levels Used in Developing Choice Experiment

\begin{tabular}{lcc}
\hline \hline Attributes & Levels & $\begin{array}{c}\text { Yes Response } \\
(\boldsymbol{\%})\end{array}$ \\
\hline \multirow{2}{*}{ Availability of range extender } & Yes & 17.2 \\
& No & 18.4 \\
Vehicle model & & \\
& eBox & 14.0 \\
Full purchase price & Civic & 22.0 \\
& & 42 \\
& $\$ 20,000$ & 31.0 \\
& $\$ 30,000$ & 10.3 \\
& $\$ 40,000$ & 9.9 \\
\hline
\end{tabular}

Each vehicle presented in the survey has also the following features

\begin{tabular}{ll}
\hline Driving range on full battery & 140 miles \\
Guaranteed minimum driving range under V2G contract & 25 miles \\
Time it takes to change battery for 50 miles of driving range & 1 hour \\
$\begin{array}{l}\text { Average length of required plug-in time per day with energy } \\
\text { dial set to sell under V2G contract }\end{array}$ & 20 hours \\
Acceleration compared to your preferred gasoline vehicle & $5 \%$ faster \\
Pollution compared to your preferred gasoline vehicle & $75 \%$ \\
Fuel cost & Like $\$ 1.00 /$ gal gas \\
Annual cash payment made to you on V2G contract & $\$ 4000$ \\
\hline
\end{tabular}

Except for the above features, the vehicle is assumed to be the same as comparable gasoline vehicle 
Table 2: Comparing Sample and Census Data ${ }^{\mathrm{a}}$

\begin{tabular}{|c|c|c|}
\hline Variable & Sample (\%) & Census (\%) \\
\hline \multicolumn{3}{|l|}{ Gender } \\
\hline Male & 43.0 & 48.7 \\
\hline \multicolumn{3}{|l|}{ Age } \\
\hline 18 to 24 & 12.0 & 12.9 \\
\hline 25 to 44 & 39.4 & 36.3 \\
\hline 45 to 64 & 34.7 & 33.9 \\
\hline 65 to 84 & 13.8 & 14.4 \\
\hline 85 or above & 0.17 & 2.5 \\
\hline \multicolumn{3}{|l|}{ Education } \\
\hline High school incomplete & 2.0 & 15.7 \\
\hline High school complete & 39.2 & 30.0 \\
\hline Some college & 21.7 & 29.3 \\
\hline BA or higher & 36.7 & 25.0 \\
\hline \multicolumn{3}{|l|}{ Type of residence } \\
\hline House & 72.8 & 69.2 \\
\hline Apartment/condo & 20.8 & 24.6 \\
\hline Mobile or other housing type & 6.4 & 6.2 \\
\hline \multicolumn{3}{|c|}{ Number of vehicles in a household } \\
\hline No vehicle & 4.2 & 8.8 \\
\hline One vehicle & 34 & 33.4 \\
\hline Two vehicles & 40.3 & 37.8 \\
\hline Three or more vehicles & 21.5 & 20.0 \\
\hline \multicolumn{3}{|l|}{ Household income } \\
\hline Less than $\$ 10,000$ & 4 & 7.2 \\
\hline$\$ 10,000-\$ 14,999$ & 3.3 & 5.5 \\
\hline$\$ 15,000-\$ 24,999$ & 10.2 & 10.6 \\
\hline$\$ 25,000-\$ 34,999$ & 13 & 10.6 \\
\hline$\$ 35,000-\$ 49,999$ & 19.1 & 14.2 \\
\hline$\$ 50,000-\$ 74,999$ & 22.5 & 18.8 \\
\hline$\$ 75,000$ - $\$ 99,999$ & 13.5 & 12.5 \\
\hline$\$ 100,000-\$ 149,999$ & 10.3 & 12.2 \\
\hline$\$ 150,000-\$ 199,999$ & 1.9 & 4.3 \\
\hline$\$ 200,000$ or more & 1.5 & 4.2 \\
\hline
\end{tabular}

Census Data Source: U.S. Census Bureau, 2008 American Community Survey

${ }^{\mathrm{a}}$ The sample has also similar distribution of population size by region. To reduce space, we did not present the numbers here. 
Table 3A: Rating Advantages of EVs ${ }^{\mathrm{a}}$

\begin{tabular}{lccc}
\hline \hline \multirow{2}{*}{ Advantages } & \multicolumn{3}{c}{ Degree it matters in respondent's purchase decision } \\
\cline { 2 - 4 } & Matters a lot & Matters some & Does not matter \\
& $(\%)$ & $(\%)$ & $(\%)$ \\
\hline Lower fuel cost & 73 & 22 & 5 \\
Lower dependence on foreign oil & 63 & 28 & 9 \\
Lower pollution & 50 & 30 & 10 \\
Avoid trip to gas station & 47 & 47 & 24 \\
Interesting new technology & 29 & 37 & 16 \\
\hline \hline
\end{tabular}

${ }^{a}$ The question used in the survey is: "Here are some of the advantages of electric versus gasoline vehicles. Please indicate which matter to you as a potential buyer."

Table 3B: Rating Disadvantages of EVs ${ }^{\mathrm{a}}$

\begin{tabular}{lccc}
\hline \hline & & & \\
Disadvantages & \multicolumn{3}{c}{ Degree it matters in respondent's purchase decision } \\
\cline { 2 - 4 } & Matters a lot & Matters some & Does not matter \\
\hline Higher purchase price & 64 & $(\%)$ & $(\%)$ \\
Lower driving range & 51 & 32 & 4 \\
Longer fill-up time & 50 & 42 & 7 \\
Unfamiliar technology & 32 & 40 & 23 \\
\hline \hline
\end{tabular}

a The question used in the survey is: "Here are some of the disadvantages of electric versus gasoline vehicles. Please indicate which matter to you as a potential buyer." 
Table 4: Definition and Descriptive Statistics of Variables Used in Regression ${ }^{\mathrm{a}}$

\begin{tabular}{|c|c|c|c|}
\hline Variables & Description & $\begin{array}{c}\% \text { in } \\
\text { Sample }\end{array}$ & $\begin{array}{c}\text { Mean } \\
\text { (SD) }\end{array}$ \\
\hline \multicolumn{4}{|c|}{ Variables in Random Utility Model $\left(\mathbf{X}_{\mathrm{nj}}\right)$} \\
\hline Constant & 1 if the respondent voted yes for the proposed V2G-EV & $17.8 \%$ & \\
\hline Yea-Correction & 1 if the survey has a yea-saying correction & $51 \%$ & \\
\hline Price & Price of the proposed V2G-EV $[\$ 20,000-\$ 70,000]$ & & $\begin{array}{l}\$ 45,246 \\
(\$ 17,214)\end{array}$ \\
\hline Civic & 1 if the model is civic; 0 if the model is eBox & $50 \%$ & \\
\hline Range Extender (RE) & 1 if the vehicle has range extender; 0 otherwise & $50 \%$ & \\
\hline \multicolumn{4}{|c|}{ Variables in Class Membership Model $\left(Z_{n}\right)$} \\
\hline Age & Age of the respondent in years & & $\begin{array}{c}45 \\
(15)\end{array}$ \\
\hline $\mathrm{CA}$ & 1 if the respondent is from California; 0 otherwise & 10.1 & \\
\hline Male & 1 if male; 0 otherwise & 43 & \\
\hline College & 1 if completed a BA or higher degree; 0 otherwise & 37 & \\
\hline Income & Household income (2009 \$) & & $\begin{array}{l}\$ 60,357 \\
(\$ 42,398)\end{array}$ \\
\hline Gas price & $\begin{array}{l}\text { Expected price of regular gasoline in } 5 \text { years (nominal } \\
\text { dollars) }\end{array}$ & & $\begin{array}{l}\$ 4.4 \\
(\$ 1.7)\end{array}$ \\
\hline Multicar & 1 if household owns 2 or more cars; 0 otherwise & 62 & \\
\hline Hybrid & 1 if household plans to buy a hybrid; 0 otherwise & 33 & \\
\hline Outlet & $\begin{array}{l}1 \text { if the respondent is very likely or somewhat likely to } \\
\text { have a place to install an outlet (charger) at their home at } \\
\text { the time of next vehicle purchase; } 0 \text { otherwise }\end{array}$ & 77 & \\
\hline Early Adopter & $\begin{array}{l}1 \text { if the respondent has a tendency to buy new products } \\
\text { that come on the market; } 0 \text { otherwise }\end{array}$ & 57 & \\
\hline Major green & $\begin{array}{l}1 \text { if respondent reported making major change in life } \\
\text { style and shopping habits in the past } 5 \text { years to help the } \\
\text { environment; } 0 \text { otherwise }\end{array}$ & 23 & \\
\hline Minor green & $\begin{array}{l}1 \text { if respondent reported making minor change in life } \\
\text { style and shopping habits in the past } 5 \text { years to help the } \\
\text { environment; } 0 \text { otherwise }\end{array}$ & 60 & \\
\hline Not green & $\begin{array}{l}1 \text { if respondent reported no change in life style and } \\
\text { shopping habits in the past } 5 \text { years to help the } \\
\text { environment; } 0 \text { otherwise }\end{array}$ & 17 & \\
\hline
\end{tabular}

${ }^{\mathrm{a}}$ Either \% or mean is shown, depending on whether the variable is continuous or discrete. 
Table 5A: Random Utility Model Results

\begin{tabular}{|c|c|c|c|c|c|c|}
\hline \multirow{3}{*}{ Variables } & \multicolumn{2}{|c|}{ "Binary Logit Model } & \multicolumn{4}{|c|}{ Latent Class Binary Logit Model } \\
\hline & \multirow[b]{2}{*}{ Coef. } & \multirow[b]{2}{*}{ T-sat } & \multicolumn{2}{|c|}{ GV-Oriented } & \multicolumn{2}{|c|}{ V2G-Oriented } \\
\hline & & & Coef. & T-sat & Coef. & T-sat \\
\hline Constant & -0.678 & -2.7 & 1.32 & 4.4 & 2.33 & 8.5 \\
\hline Yea-Correction & -0.833 & -9.1 & -0.10 & -0.62 & -1.55 & -9.6 \\
\hline Civic & 0.616 & 8.8 & 1.15 & 4.5 & 0.55 & 3.7 \\
\hline Range Extender & 0.236 & 3.5 & 0.44 & 1.9 & 0.33 & 2.2 \\
\hline Price (000) & -0.043 & -25.6 & -0.14 & -9.5 & -0.051 & -10.7 \\
\hline Age & -0.023 & -7.6 & & & & \\
\hline Being from $\mathrm{CA}$ & 0.333 & 2.7 & & & & \\
\hline Male & 0.239 & 2.7 & & & & \\
\hline College & -0.156 & -1.7 & & & & \\
\hline Income (0000) & 0.14 & 1.32 & & & & \\
\hline $\begin{array}{l}\text { Gasoline price } \\
\quad(\$ / \text { gal })\end{array}$ & 0.032 & 1.35 & & & & \\
\hline Hybrid & 0.37 & 4.1 & & & & \\
\hline Outlet & 0.805 & 6.9 & & & & \\
\hline Multicar & -0.24 & -2.6 & & & & \\
\hline Major green & 0.92 & 6.2 & & & & \\
\hline Minor green & 0.39 & 2.9 & & & & \\
\hline Early adopter & 0.38 & 4.4 & & & & \\
\hline \multicolumn{2}{|c|}{ Latent Class Size (\%) } & & \multicolumn{2}{|c|}{73} & \multicolumn{2}{|c|}{27} \\
\hline $\mathrm{N}$ & \multicolumn{2}{|c|}{6058} & \multicolumn{4}{|c|}{6058} \\
\hline $\operatorname{LL}(\beta)$ & \multicolumn{2}{|c|}{-2363.3} & \multicolumn{4}{|c|}{-2213.7} \\
\hline
\end{tabular}

${ }^{\text {a }}$ Reference category= "not green"

Note: the standard and latent class binary logit models have the same set of attributes, but differ in how the individual specific attributes (attributes that vary only across respondents) are specified. In the standard logit model, the effect of individual specific variables on the choice variable are specified directly and the parameters are part of the choice model. In the latent class model, the effect of individual specific variables is captured through their effect on class membership and the parameters are presented in Table 6 . 
Table 5B: Class Membership Model Results (GV-oriented is the normalized class)

\begin{tabular}{|c|c|c|c|}
\hline Variables & Coefficient & T-Stat. & $\begin{array}{l}\text { Odds } \\
\text { Ratio } \\
\end{array}$ \\
\hline Class membership constant & -1.77 & -3.9 & 0.17 \\
\hline Age & -0.04 & -6.3 & 0.96 \\
\hline Being from $\mathrm{CA}$ & 0.73 & 2.8 & 2.1 \\
\hline Male & 0.36 & 2.1 & 1.4 \\
\hline College & -0.47 & -2.4 & 0.63 \\
\hline Income (000) & 0.0006 & 0.27 & 1.0 \\
\hline Gasoline price ( \$/gal) & 0.10 & 2.3 & 1.1 \\
\hline Hybrid & 0.61 & 3.4 & 1.8 \\
\hline Outlet & 1.22 & 5.2 & 3.4 \\
\hline Multicar & -0.52 & -2.9 & 0.6 \\
\hline Major green ${ }^{\mathrm{a}}$ & 1.41 & 5.3 & 4.1 \\
\hline Minor green ${ }^{\mathrm{a}}$ & 0.40 & 1.6 & 1.5 \\
\hline Early adopter & 0.52 & 3.1 & 1.7 \\
\hline \multicolumn{4}{|l|}{$\mathrm{N}=6058$} \\
\hline $\operatorname{LL}(\beta)=-2213.7$ & & & \\
\hline
\end{tabular}

See Table 4 for variable definitions.

${ }^{\text {a }}$ Reference category= "not green" 
Table 6: Battery Cost Forecasts and Estimates

\begin{tabular}{lllrr}
\hline \hline \multirow{2}{*}{ Year } & \multicolumn{2}{l}{ Reference Case Scenario } & \multicolumn{2}{l}{ High Tech Case Scenario } \\
\cline { 2 - 5 } & $\begin{array}{l}\text { Forecast } \\
(\$ / \mathrm{kWh})\end{array}$ & $\begin{array}{l}\text { Total Cost } \\
\text { Estimate }^{\mathrm{a}}\end{array}$ & $\begin{array}{r}\text { Forecast } \\
(\$ / \mathrm{kWh})\end{array}$ & $\begin{array}{r}\text { Total Cost } \\
\text { Estimate }^{\mathrm{a}}\end{array}$ \\
\hline 2013 & $\$ 893$ & $\$ 31,255$ & $\$ 677.7$ & $\$ 23,720$ \\
2015 & $\$ 684.5$ & $\$ 23,958$ & $\$ 401.4$ & $\$ 14,049$ \\
2018 & $\$ 517$ & $\$ 19,985$ & $\$ 312.9$ & $\$ 10,952$ \\
\hline \hline
\end{tabular}

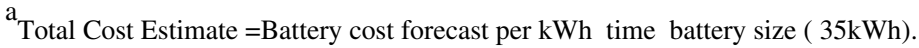

Source (\$/kWh): U.S. Energy Information Administration's (EIA) Annual Energy Outlook 2012 (AEO2012).

http://www.eia.gov/todayinenergy/detail.cfm?id=6930 (last accessed: Sept., 2013).

Table 7: Non-Battery Cost of V2G-EVs

\begin{tabular}{|c|c|c|c|}
\hline Vehicle Model & Base Price & Added Cost $^{\mathrm{a}}$ & Total Cost \\
\hline eBox without $\mathrm{RE}^{\mathrm{b}}$ & $\$ 17,920$ & $\$ 2,600$ & $\$ 20,520$ \\
\hline eBox with $\mathrm{RE}^{\mathrm{b}}$ & $\$ 17,920$ & $\$ 10,000$ & $\$ 30,520$ \\
\hline Civic without $\mathrm{RE}^{\mathrm{c}}$ & $\$ 20,815$ & $\$ 2,600$ & $\$ 23,415$ \\
\hline Civic with $\mathrm{RE}^{\mathrm{c}}$ & $\$ 20,815$ & $\$ 10,000$ & $\$ 30,815$ \\
\hline
\end{tabular}

${ }^{\mathrm{a}}$ For vehicles with range extender, the added cost is the cost of electric motor and related components. For vehicles without range extender, added costs $=$ cost of electric motor and related vehicles - cost of gasoline engine and components. Based on estimates from Werber et al., (2009), we used $\$ 10,000$ for cost of motor and related components and $\$ 7,400$ for cost of gasoline engine and related components (transmission).

$\mathrm{b}$

${ }^{c}$ The base price for Civic is based on the 2013 price of Honda Civic XL Sedan

Available at: http://www.motortrend.com/new_cars/ 
Table 8: Comparing WTP for and Estimated Cost of V2G-EVs

\begin{tabular}{|c|c|c|c|c|c|c|c|}
\hline \multirow{3}{*}{ Vehicle Type } & \multirow{3}{*}{$\begin{array}{l}\text { Top } 1 \% \\
\text { WTP }^{\mathrm{a}}\end{array}$} & \multicolumn{6}{|c|}{$\begin{array}{c}\text { Total Cost } \\
\text { (Battery Costs }+ \text { Non-battery cost) }\end{array}$} \\
\hline & & \multicolumn{3}{|c|}{ Reference Case Scenario } & \multicolumn{3}{|c|}{ High Tech Case Scenario } \\
\hline & & 2013 & 2015 & 2018 & 2013 & 2015 & 2018 \\
\hline eBox without RE & $\$ 14,116$ & $\$ 51,775$ & $\$ 44,478$ & $\$ 40,502$ & $\$ 44,240$ & $\$ 34,569$ & $\$ 31,472$ \\
\hline eBox with RE & $\$ 20,083$ & $\$ 59,175$ & $\$ 51,878$ & $\$ 47,902$ & $\$ 51,640$ & $\$ 41,969$ & $\$ 38,872$ \\
\hline Civic without RE & $\$ 24,417$ & $\$ 54,670$ & $\$ 47,373$ & $\$ 43,397$ & $\$ 47,135$ & $\$ 37,464$ & $\$ 34,367$ \\
\hline Civic with RE & $\$ 30,384$ & $\$ 61,440$ & $\$ 54,143$ & $\$ 50,167$ & $\$ 53,905$ & $\$ 44,234$ & $\$ 41,137$ \\
\hline
\end{tabular}




\section{Choice 1 of 2 Choices}

Suppose the following V2G vehicle with the attributes shown below was available on the market in your area.

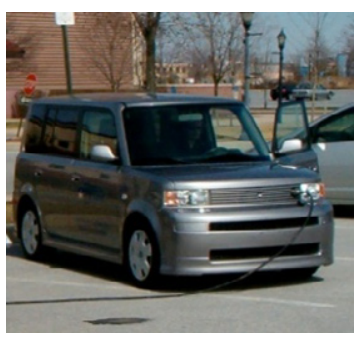

\begin{tabular}{|l|l|}
\hline \multicolumn{1}{|c|}{ V2G Electric Vehicle Attributes } & Values \\
\hline Driving range on full battery & 140 miles \\
\hline Guaranteed minimum driving range on V2G contract & 25 miles \\
\hline Back-up gas engine on board for use if battery is discharged & No \\
\hline Fuel cost & Like \$1.00/gal gas \\
\hline Time it takes to charge battery for 50 miles of driving range & 1 hour \\
\hline $\begin{array}{l}\text { Average length of required plug-in time per day with energy dial set to sell on V2G } \\
\text { contract }\end{array}$ & 20 hours \\
\hline Acceleration compared to your preferred conventional gasoline vehicle & $5 \%$ faster \\
\hline Pollution compared to your preferred conventional gasoline vehicle & $75 \%$ lower \\
\hline Annual cash payment made to you on V2G contract & $\$ 4,000 /$ year \\
\hline Full purchase price & $\$ 50,000$ \\
\hline
\end{tabular}

Would you purchase this vehicle in the next 5 years? Please treat this choice as though it were an actual purchase with real dollars on the line and except for the features listed above assume the vehicle comes with a standard set of options.

. Yes, I would buy it for $\$ 50,000$

. No, I would not buy it for $\$ 50,000$

. I like many of the features of this vehicle and the idea of electric vehicles, but I could/would not pay $\$ 50,000$

Figure 1: Sample V2G-EV Choice Question 


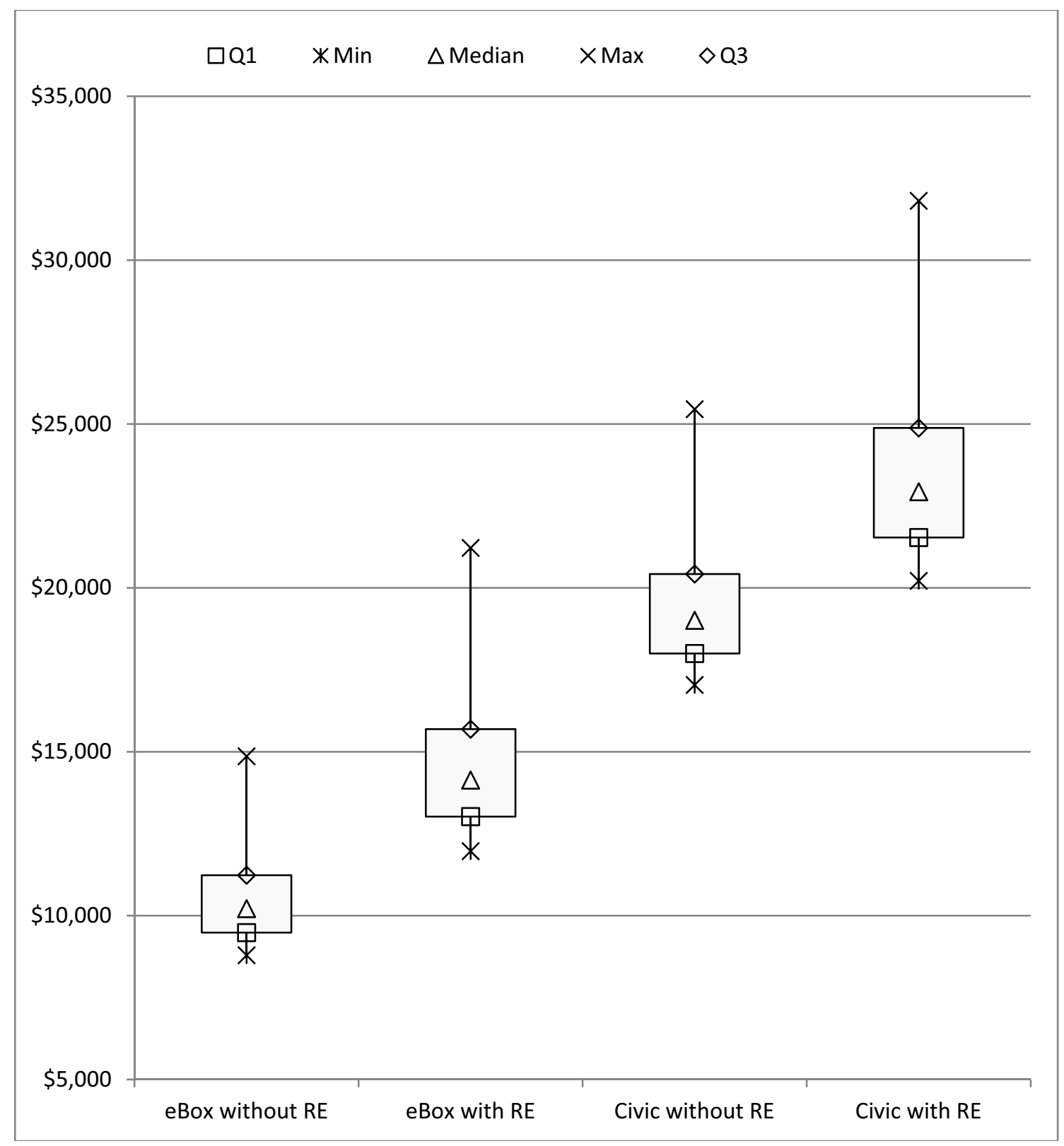

Figure 2: Distribution of WTP for Alternative V2G-EV Specifications 


\section{References}

Beggs S, Cardell S, Hausman J. Assessing the Potential Demand for Electric Cars. J Econometrics 1981; 16: 1-19.

Bishop JDK, Axon CJ, Bonilla D, Tran M, Banister D, McCulloch MD. Evaluating the Impact of V2G Services on the Degradation of Batteries in PHEV and EV. Applied Energy 2013; 111: 206-218.

Blamey RK, Bennett JW, Morrison MD. Yea-Saying in Contingent Valuation Surveys. Land Economics 1999; 75 (1): 126-141.

Boxall PC, Adamowicz WL. Understanding Heterogeneous Preferences in Random Utility Models: A Latent Class Approach. Environmental and Resource Economics 2002; 23(4): 421-446.

Boyle KJ, MacDonald HF, Cheng H, McCollum DW. Bid Design and YeaSaying in Single-bounded Dichotomous Questions. American Journal of Agricultural Economics 1998; 74: 49-64.

Briones A, Francfort J, Heitmann P, Schey M, Schey S, Smart J. Vehicle-to-Grid (V2G) Power Flow. Idaho National Laboratory, 2012; DE-AC07$05 \mathrm{ID} 14517$.

Brooks A. Vehicle-to-Grid Demonstration Project: Grid Regulation Service with a Battery Electric Vehicle. Report, AC Propulsion, 2002.

Brownstone D, Train K. Forecasting New Product Penetration with Flexible Substitution Patterns. J Econometrics 1999; 89: 109-29.

Bunch DS, Bradley M, Golob TF, Kitamura R, Occhiuzzo GP. Demand for Clean-Fuel Vehicles in California: A Discrete-Choice Stated Preference Pilot Project. Transportation Research Part A 1993; 27 (3): 237- 253

Calfee JE. Estimating the Demand for Electric Automobiles Using Disaggregated Probabilistic Choice Analysis. Transportation Research B: Methodological 1985; 19(4):287-301.

De Losi Rios A, Goentzel J, Nordstorm KE, Siegert CW. Economic Analysis of Vehicle-to-Grid (V2G)-Enabled Fleets Participating in the Regulation Service Market. Innovative Smart Grid Technologies (ISGT) 2012; IEEE PES.

EIA. Annual Energy Outlook 2012 with Projections to 2035; September 2013. 
Ewing G, Sarigollu E. Car Fuel-Type Choice under Travel Demand Management and Economic Incentives. Transport Research D 1998; 3(6):429-444.

Federal Energy Regulation Commission. Order No. 755.137 FERC 61,604, 18 CFR Section 35 Docket Nos. RM11-7-000, AD10-11-000.

Hidrue M K, Parsons GR, Kempton W, Gardner MP. Willingness to Pay for Electric Vehicles and Their Attributes. Resource and Energy Economics 2011; 33(3):686-705.

Holmes TP, Kramer RA. An Independent Sample Test of Yea-saying and Starting Point Bias in Discrete-choice Contingent Valuation. J Environmental Economics and Management 1995; 29: 121-132.

Kempton, W. and J. Tomić, 2005. Vehicle to Grid Fundamentals: Calculating Capacity and Net Revenue. Journal of Power Sources, 144 (1): 268-279.

Lefeng S, Qian Z, Yongjian P. The Reserve Trading Model Considering V2G Reverse. Energy 2013; 59: 50-55.

Lund H, Kempton W. Integration of Renewable Energy into the Transport and Electricity Sector Though V2G. Energy Policy 2008; 36: 3578 -3587.

Noel L, McCormack R. A cost benefit analysis of a V2G-capable electric school bus compared to a traditional diesel school bus. Applied Energy 2014; 126: $246-265$.

Parsons GR, Hidrue MK, Kempton W, Gardner MP. Willingness to Pay for Vehicle-to-Grid (V2G) Electric Vehicles and Their Contract Terms. Energy Economics 2014; 42: 313 - 324.

Pearre N S, Kempton W, Guensler RL, Elango VV. Electric Vehicles: How much Range is Required for a Day's Driving? Transportation Research Part C 2011; 19:1171-1184.

Peterson SB, Apt J, Whitacre JF. Lithium-ion Battery Cell Degradation Resulting from Realistic Vehicle and Vehicle-to-Grid Utilization. J Power Sources 2010; 195: 2385 - 2392 .

Sioshansi R, Denholm P. The Value of Plug-in Hybrid Electric Vehicles as Grid Resource. The Energy Journal 2010; 31(3): 1-24.

Sovacool B K, Hirsh RF. Beyond Batteries: An Examination of the Benefits and Barriers to Plug-in Hybrid Electric Vehicles (PHEVs) and Vehicle-to-Grid (V2G) Transition. Energy Policy 2009; 37: 1095-1103. 
Swait J. Advanced Choice Models, in: Barbara J. Kanninen (Eds.), Valuing Environmental Amenities Using Stated Choice Studies. Springer, Dordrecht 2007; 229-29.

Weis A, Jaramillo P, Michalek J. Estimating the potential of Controlled Plug-in Hybrid Electric Vehicle Charging to Reduce Operational and Capacity Expansion Cost for Electric Power System with High Wind Penetration. Applied Energy 2014; 115: 190-204.

Werber M, Fischer M, Schwartz PV. Batteries: Lower Cost than Gasoline? Energy Policy 2009; 37: 2465-2468.

White CD, Zhang KM. Using Vehicle-to-Grid Technology for Frequency Regulation and Peak-Load Reduction, J Power Sources 2011; 196: 39723980 . 